\title{
PELAKSANAAN PERLINDUNGAN JAMINAN KECELAKAAN DAN KESELAMATAN KERJA PADA SUKSES ABADI
}

\author{
Oleh \\ Ida Ayu Sintya Maharani \\ I Wayan Wiryawan \\ Program Kekhususan Hukum Bisnis Fakultas Hukum Universitas \\ Udayana
}

\begin{abstract}
ABSTRAK
Pada pembanguna ekonomi pada sektor penyediaan barang dan jasa mampu meningkatkan pertumbuhan ekonomi karena dapat menyediakan serta meningkatkan penghasilan pekerja.Kegiatan usaha dibidang penyedia barang dan jasa,memiliki peran cukup penting dalam berjalanya suatu bisnis penyediaan barang dan jasa. Peningkatan produksifitas pekerja tergantung dari jamianan kecelakaan dan keselamatan pekerja.Penelitian ini menggunakan metode penelitian hukum yuridis empiris,yaitu pendekatan dengan melihat sesuatu kenyataann hukum didalam masyarakat berdasarkan dari teoriteori hukum dengan melakukan penelitian secara langsung ke lapangan guna mendapatkan kebenaran yang akurat.Sumber data diperoleh dari penelitian langsung yang berbentuk observasi wawancara, selain itu digunakan literature-literature serta perundang-undangan yng berlaku. Penelitian ini dilakukan di UD.Sukses Abadi dengan tujuan pelaksaanaan perlindungan jaminan kecelakaan dan keselamatan kerja pada UD.Sukses Abadi.Hasil yanmg diperoleh dari penelitian ini ialah UD.Sukses Abadi belum melaksanakan perlindungan jaminan kecelakaan dan keselamatan kerja.
\end{abstract}

Kata Kunci: Perlindungan hukum,Pekerja,Kecelakaan dan Kesehatan Kerja.

\footnotetext{
${ }^{1}$ Artiket ini adalah Ringkasan Skripsi

${ }^{2}$ Ida Ayu Sintya Maharani

${ }^{3}$ I Wayan Wiryawan
} 


\begin{abstract}
ABTRACT
Economic development in the supply sector of goods and services is able to increase economic growth because it can provide and increase the income of workers. Business activities in the field of goods and services providers have an important role in the business of providing goods and services. Increased productivity of workers depends on accidents and worker safety. This study uses empirical juridical legal research methods, namely the approach by looking at something legal in society based on legal theories by conducting research directly into the field to obtain accurate truths. Data sources obtained from direct research in the form of interview observations, in addition to the literature used and applicable legislation. This research was carried out at UD. Sukses Abadi with the aim of implementing accident insurance and work safety protection at UD. Eternal success. The results obtained from this study were that UD. Sukses Abadi had not implemented accident insurance and work safety protection.
\end{abstract}

Keywords: Legal protection, Workers, Accidents and Occupational Health

\title{
I.PENDAHULUAN
}

\subsection{Latar Belakang Masalah}

Dalam perkembangan jaman dan kemajuan teknologi saat ini muncul perusahaan-perusahaan baru dengan modal yang kuat serta diimbangi dengan tenaga kerja yang potensial agar bisa bersaing dengan para kompetitor.Dimana kemajuan dari perusahaan tersebut bergantung pada orang-orang yang berada didalam perusahaan tersebut, Salah satu 
di antaranya adalah tenaga kerja. Dalam Undang-undang No.13 Tahun 2003 tentang ketenagakerjaan mendefinisikan tenaga kerja adalah setiap orang yang mampu melaksanakan pekerjaan guna menghasilkan barang dan atau jasa baik untuk memenuhi kebutuhan sendiri maupun masyarakat.

Akan tetapi kemampuan pekerja dalam menghasilkan pekerjaan yang optimal bagi perusahaan dapat berkurang atau bisa hilang karena berbagai macam halangan salah satunya karena sakit dan juga kecelakaan.

Kesejahteraan merupakan suatu pelayanan sosial yang disediakan perusahaan bagi karyawan beserta keluarganya. Tujuannya adalah untuk memelihara serta meningkatkan semangat dan produktivitas kerja yang dilaksanakan melalui program kesejahteraan sosial ${ }^{4}$. Salah satu aspek pada kesejahteraan kerja adalah keselamatan dan kesehatan kerja terutama di era industrialisasi ini ${ }^{5}$.

UD Sukses Abadi adalah salah satu Usaha Dagang yang bergerak dibidang Engineering Hotel.Dalam pelaksanaan produksi pada Usaha dagang Sukses Abadi peristiwa-peristiwa yang tidak terduga terjadi seperti kecelakaan kerja. Namun kasus-kasus kecelakaan kerja pada perusahaan ini tidak sampai membuat tenaga kerja cacat atau bahkan merenggut nyawa. Kasus kecelakaan kerja yang terjadi pada UD.Sukses Abadi seperti halnya tergencet oleh mesin sewaktu mengakat barang, tersetrum pada saat memperbaiki mesin yang rusak, selain masalah yang terjadi karena pekerjaan, adapula gangguan kesehatan yang mengancam para pekerja yaitu sakit pada bagian pencernaan dan bagian pernafasan. Yang disebabkan olehd partikel-partikel kecil yang

${ }^{4}$ Burhannudin ATayibnapis,1995, Administrasi Kepegawaian: Suatu Tinjauan Analitik, Pradnya Paramita, Jakarta, h. 298

${ }^{5}$ Basir Barthos, Manajemen Sumber Daya Manusia Suatu Pendekatan Makro,h.137 
dapat terhirup dan menyumbat saluran pernafasan pada saat memperbaiki mesin, yang nantinya akan lebih membahayakan keselamatan dan kesehatan para tenaga kerja.

Sehingga Program Keselamatan dan Kesehatan Kerja harus dibuat manajemen UD Sukses Abadi dengan tepat untuk meningkatkan kinerja pegawainya.

\subsection{Tujuan}

1. Mengetahui dengan adanya kebijakan pelaksanaan perlindungan kecelakaan dan kesehatan tenaga kerja

2. Mengetahui hambatan-hambatan yang dihadapi dalam pelaksanaan perlindungan jaminan kecelakaan dan kesehatan tenaga kerja

\section{ISI MAKALAH}

\subsection{Metode Penulisan}

\subsubsection{Jenis Penelitian}

Jenis penelitan yang digunakan dalam penelitian skripsi ini menggunakan penelitian yuridis empiris dimana data-data yang diperoleh berasal dari fakta-fakta yang terjadi di UD Sukses Abadi.Penelitan hukum empiris dilakukan untuk memperoleh data primer dengan melakukan wawancara.

\subsubsection{Jenis Pendekatan}

Penulis menggunakan dua jenis pendekatan yaitu Pendekatan Fakta dan Pendekatan analisis Konsep Hukum. 


\subsubsection{Sumber bahan hukum}

Sumber bahan hukum yang digunakan dalam penulisan ini adalah bahan hukum primer dan bahan hukum sekunder.

1. Bahan hukum primer terdiri dari peraturan perundang-undangan.

2. Bahan hukum sekunder didapat dari buku-buku hukum dan jurnaljurnal hukum

\subsubsection{Teknik pengumpulan data}

Teknik pengumpulan yang dipergunakan ialah teknik studi dokumen, teknik wawancara dan teknis observasi langsung.

\subsubsection{Teknik pengolahan dan analisis data}

Seluruh data yang dikumpulkan dalam penelitian ini selanjutnya diolah dan dianalisis secara kualitatif. analisa kualitatif merupakan analisa yang tidak menggunakan angka-angka tetapi berbentuk penjelasan serta pendeskripsian ${ }^{6}$.

\subsection{HASIL DAN ANALISIS}

\subsubsection{PELAKSANAAN PERLINDUNGAN JAMINAN KECELAKAAN DAN KESEHATAN KERJA PADA UD SUKSES ABADI}

Menurut penjelasan Bapak Ida Bagus Gede Budiartha,Pemilik UD. Sukses Abadi, UD. Sukses Abadi ialah perusahaan yang bergerak di bidang jasa penyediaan barang dan juga sekaligus pengirimannya. Adapun lebih detail barang yang di sediakan oleh UD.Sukses Abadi ialah barang enginerreng yang dikirim ke berbagai hotel yang berada pada daerah pariwisata di Bali yang didirikan pada tanggal 21 Juni Tahun 1998 oleh Bapak Ida Bagus Gede Budiarta.UD. Sukses Abadi beralamat di Jalan

${ }^{6}$ Amirudin dan Zainal Asikin, 2004, Pengantar Metode Penelitian Hukum, PT. Raja Grafindo Persada, Jakarta, h.167 
Raya Sesetan Gang No. 16, Badung-Bali. Sebagaimana struktur organisasi UD.Sukses Abadi disebutkan bahwa yang merupakan Pemilik UD. Sukses Abadi adalah Bapak Ida Bagus Gede Budiarta .Dalam menjalankan tugas-tugasnya Pemilik UD dibantu oleh Ibu Agung Mas.sebagai General Manager Ibu Agung Mas yang melakukan pengawasan tentang kinerja ataupun masalah para tenaga kerja dan Ibu Agung Mas juga sekaligus bekedudukan sebagai Menager operasi,melakukan pengawasan terhadap pelaksanaan kegiatan-kegiatan.Untuk bagian keuangan UD.Sukses Abadi dijalankan oleh Ibu Ni Wayan Murdani. Pada UD. Sukses Abadi sebagai pihak yang mengintruksikan kegiatan penyedia dan pengiriman barang-barang enggeneering ke hotelhotel pariwisata yang akan diselenggarakanyaitu bagian operasional.Sedangkan, pengawasan kinerja pegawai,keselamatan dan kesehatan kerja dilaksanakan oleh Ibu Agung Mas sendiri selaku General Menager. Menurut General Menager UD. Sukses Abadi, Ibu Agung Mas dijelaskan bahwa UD. Sukses Abadi,merupakan perusahaan yang bergerak dibidang jasa penyedia dan pengiriman barang engineering pariwisata yang didirikan oleh Bapak Ida Bagus Gede Budiarta pada tahun1998

Di dalam Undang-undang nomor 13 tahun 2003 tentang ketenagakerjaan telah disebutkan tentang hak dan kewajiban seorang pekerja dalam melaksanakan pekerjaannya, Adapun Undang-undang tersebut berfungsi untuk melindungi dan membatasi status hak dan kewajiban para pekerja dari para pemberi kerja (Pengusaha) yang sesuai dengan harkat dan martabat kemanusiaan dalam ruang lingkup kerja. Keselamatan kerja adalah bagian dari ilmu kesehatan yang bertujuan agar tenaga kerja memperoleh keadaan kesehatan yang sempurna,baik 
fisik maupun sosial,sehingga dapat memungkinkan dapat bekerja secara optimal(Depnaker, 1994/1995:11). ${ }^{7}$

Menurut hasil wawancara dengan $\mathrm{Ni}$ Wayan Murdani Staff Accouting UD Sukses Abadi menyatakan bahwa:

1. Pengusaha UD Sukses Abadi memberikan upah kepada pekerjanya tertinggi yaitu Satu juta Sembilan ratus ribu rupiah yang dibayarkan setiap satu bulan sekali sehingga satu bulan.

2. Adapun perusahaan dalam keselamatan dan kesehatan kerja, pengusaha telah menyediakan P3K;

a. UD.Sukses Abadi mendaftarkan pekerjanya sebanyak 5 orang pekerja/buruh pada tanggal 8 oktober 2014 pada jaminan sosial, yang diikuti berupa:

a. Jaminan Kecelakaan Kerja

b. Jaminan Kematian

c. Jaminan Hari Tua

Pekerja baru pada UD Sukses Abadi Ibu Mariati yang kurang lebih bekerja selama 1 tahun 60 hari. Gaji yang didapatkan yaitu $\mathrm{Rp}$ 1.250.000.Jumlah Gaji tersebut tidak memenuhi standar Upah Minimum pada Provinsi Bali. Dalam Lampiran Peraturan Gubernur Bali Nomor 67 Tahun 2016 tentang Upah Minimum Kabupateb/kota Tahun 2016 menyebutkan bahwa UMK Kabupaten Badung sebesar Rp 2.499.580 (Dua Juta Empat ratus Sembilan Puluh Sembilan Lima Ratus Delapan Puluh Rupiah). Akan tetapi pengusaha diharuskan tetap memperhatikan peraturan perundang-undangan yang berlaku yaitu tidak diperbolehkan membayar upah lebih rendah dari Upah Minimum yang berlaku di daerah setempat. ${ }^{8}$

\footnotetext{
${ }^{7}$ Eko Wahyudin Dan Wiwin Yulianingsih,2016,Hukum Ketenagakerjaan,Sinar Grafika,Jakarta,h.36.

'Indriarsono, Rdan M.J Sapptenno, 1996,Hukum Perburuhan(Perlindungan Hukum Bagi TenagaKerjadalamProgramJaminanSosial Tenaga Kerja),Karunia, Surabaya, h.21
} 
Jaminan sosial ketenagakerjaan seperti keselamatan dan kesehatan kerja, Untuk pendaftaran ke Badan penyelenggara Jaminan Sosial, Ud.Sukses Abadi telah mendaftarkan pekerjanya hanya 5 orang, hal tersebut dikarenakan faktor dari pekerja tersebut yang tidak ingin ikut program jaminan sosial tenaga kerja. hal tersebut dikarenakan pekerja UD.Sukses Abadi tidak berkenan gaji ataupun upahnya dipotong bagian perusahaan. Padahal seluruh tenaga kera di Indonesia diwajibkan menjadi bagian peserta BPJS Ketenagakerjaan.Menurut Undang-Undang No 24 Tahun 2011 Pasal 15 ayat (2) yang menyetakan bahwa setiap perusahaan (Pemberi kerja) diwajibkan untuk mendaftarkan seluruh karyawannya menjadi peserta BPJS Kesehatan, tanpa terkecuali. Setiap perusahaan yang tidak mengikutsertakan karyawannya dalam program BPJS ketanagakerjaan akan memperoleh sanksi administratif berupa:

1. Teguran tertulis yang dilakukan oleh BPJS.

2. Denda yang dilakukan oleh BPJS.

3. Tidak mendapat pelayanan publik tertentu yang akan dilakukan oleh Pemerintah atas permintaan BPJS. ${ }^{9}$

Sanksi tidak mendapat pelayanan publik tertentu yang dikenai kepada Pemberi Kerja meliputi:

1. Perizinan terkait usaha.

2. Izin yang diperlukan dalam mengikuti tender proyek

3. Izin memperkerjakan tenaga kerja asing

4. Izin perusahaan penyedia jasa pekerja/buruh.

5. Izin Mendirikan Bangunan (IMB). ${ }^{10}$

\footnotetext{
${ }^{9}$ Sendjum, H.Manulang, 2008, Pokok-Pokok Hukum KetenagakerjaandiIndonesia,Cet.III, RinekaCipta, Jakarta, h. 32

${ }^{10}$ Ginting,Jamin, 2007, HukumPerseroanTerbatas(UndangUndangNomor4OTahun 2007),PT. CitraAdityaBakti,Bandung, h. 41
} 
Menurut penjelasan Bapak Ida Bagus Ketut Widiarta,bahwa faktor-faktor yang menunjang pelaksanaan Keselamatan dan Kesehatan kerja pada Sukses Abadi ialah karena di lingkungan perusahaan ini mendapat dukungan sangat positif oleh pemilik UD Sukses Abadi yaitu Bapak Ida Bagus Gede Budiarta,staff pemimpin dan semua karyawan yang bekerja pada perusahaan ini.Demikian juga sudah tertuang dalam aturan peraturan perusahaan mengenai Keselamatan dan Kesehatan Kerja sehingga perusahaan dapat lebih mempertanggung jawabkannya.(Wawancara Tanggal 7 Juni2018)

Ditinjau dari kaedah hokum atau peraturan itu sendiri,keselamatan dan kesehatan kerja telah diatur dalam Undang-Undang Nomor1 Tahun1970 tentang Keselamatan Kerja dalam Pasal2 ayat (1) "yang diatur dalam Undang-undang ini ialah keselmatan kerja dalam segala tempat kerja,baik di darat,di dalam tanah,dipermukaan air,di dalama air maupun di udara,yang berada diwilayah kekuasaan hukum Republik Indonesia". Hal ini menandakan bahwa perusahaan sudah bertanggung jawab atas keselamatan dan kesehatan kerja pekerjanya. Pada umumnya terdapat 2 (dua) faktor yang menjadi faktor penghambat Pelaksanaan Keselamatan dan Kesehatan kerja yaitu,individu atau sumber daya manusia yang tidak mendukung,dalam hal ini maka perlu dilakukan pembinaan yaitu dengan mengerjakan tenaga kerja dengan tepat dan yang kedua adalah, lingkungan tempat kerja yang tidak mendukung,dalam hal lingkungannya tidak mendukung,yaitu tersedianya alat pelindung dan kondisi yang tidak mendukung pelaksanaan Kecelakaan dan Kesehatan kerja. Menurut Bapak Ida Bagus Gede Budiarta, menegaskan bahwa salah satu faktor penghambat terlaksananya keselamatan dan kesehatan kerja 
dalam bidang hukum adalah pekerja yang awam atau kurang mengerti akan aturan-aturan hukum mengenai keselamatan dalam mengemudi, sehingga dalam pelaksanaannya menjadi suatu hal yang tidak dimengerti dan dipahami dengan oleh pekerja khususnya sopir pengantar barang.Sedangkan dalam melaksanakan jaminan kesehatan kerja,yang menjadi faktor penghambatnya yaitu terdapat pekerja baru yang tidak disiplin dalam memberikan data dirinya beserta keluarganya secara lengkap yang akan di daftarkan oleh perusahaan kepada BPJS, sehingga proses pendaftarannya menjadi terhambat.

Selainitu,terdapat juga kendala lain yang dikategorikan sebagai faktor penghambat pelaksanaan keselamatan dan kesehatan kerja yang dirasakan oleh pekerja Menurut Bapak I Gusti Agung Eka Purnama,salah satu pekerja di UD Sukses Abadi, bahwa ia mengeluhkan kurang praktis dan ribetnya prosedur klaim jaminan rawat inap kecelakaan yang diberikan oleh BPJS,prosedur klaimBPJS mengharuskan untuk melapor ke perusahaan tidak boleh lebih dari 1x24 jam dan juga biaya klaim yang keluar dari BPJS tidak sesuai dengan yang sudah dibayarkan peserta kepada BPJS.Sehingga harus meminta bantuan kepada perusahaan untuk melunasi kekurangan pembayaran rumah sakit.

Sebagaimana di jelaskan di atas bahwa yang menjadi salah satu faktor yang menghambat pelaksanaan perlindungan jaminan kecelakaan dan kesehatan kerja pada UD Sukses Abadi adalah faktor Kesadaran terhadap aturan hukum.Untuk meningkatkan kesadaran hukum,upaya yang dilakukan yaitu dengan melakukan bimbingan melalui penyuluhan/sosialisasiserta pelatihan kemampuan untuk pemahaman terhadap aturan hukum. Adapun upaya lain yang 
dilakukan perusahaan untuk menyelesaikan hambatan terhadap pelaksanaan perlindungan jaminan kecelakaan dan kesehatan kerja di UD.Sukses Abadi ialah dalam hal pengajuan klaim BPJS,perusahaan berupaya akan melakukan semaksimal mungkin untuk membantu proses pengklaiman BPJS jika pekerjanya mengalami hambatan dalam mengurus klaim jaminan rawat inap dengan sesegera mungkin untuk mengisi formulir BPJS 3 atau formulir laporan kecelakaan yang tidak lebih dari 1x24 jam sejak terjadinya kecelakaan, sehingga dapat mempercepat proses klaim.

\section{III.PENUTUP}

\subsection{Kesimpulan}

1. Bahwa UD. Sukses Abadi telah menjalankan pelaksanaan perlindungan jaminan kecelakaan dan kesehatan kerja semua pekerja, UD.Sukses Abadi juga bertanggung jawab penuh atas semua pekerjanya terhadap keselamatan dan kesehatan.

2. UD. Sukses Abadi telah melaksanakan perlindungan jaminan kecelakaan dan kesehatan terhadap pekerjanya sesuai dengan peraturanperundang-undangan yang berlaku, denga nmendaftarkan dan mengikutsertakan semua pekerjanya beserta anggota keluarganya kedalam BPJS.

3. Adapun hambatan yang dihadapi oleh UD. Sukses Abadi dalam pelaksanaan perlindungan jaminan kecelakaan dan kesehatan kerja yaitu,faktor individu/sumber daya manusia yang kurang memahami dan mengerti arti pentingnya keselamatan dan kesehatan kerja.Sopir yang mengirim barang-barang yang di pesan pada UD.Sukses Abadi masih kurang mengerti terhadap aturan hukum yang berlaku, selain rendahnya kesadaran hukumoleh sopir pengirim barang dalam menjalankan 
pekerjaannya yang menjadi penghambat lainnya yaitu, kurang displinnya calon peserta baru(tenagakerjabaru)BPJS menyerahkan data diri beserta keluarganya kepada perusahaan sehingga menghambat perusahaan dalam menjalankan kewajibannya.

\subsection{Saran}

1. UD.Sukses Abadi di sarankan agar memberi tunjangan kecelakaan dan kesehatan kerja kepada pegawai tidak tetap dan mengintruksikan semua karyawan/tenaga kerja untuk mengikuti program BPJS pribadi demi kelancaran pelaksanaan keselamatan dan kesehatan kerja apabila karyawan belum bisa didaftarkan oleh perusahaan.

2. Disarankan agar UD. Sukses Abadi untuk memberikan perhatian dan pengawasan terhadap pekerjanya, serta meningkatkan pelatihan-pelatihan yang dilakukan Dalam hal proses klaim BPJS yang ribet dan berbelit-belit disarankan agar pemerintah segera memperbaiki maupun merevisi peraturan mengenai persyaratan pengajuan klaim jaminan kesehatan rawat inap kecelakaan peserta/anggota BPJS, sehingga dapat mempermudah anggota BPJS dalam pengajuan klaim.

3. Pemberian sanksi yang tegas terhadap pekerja atau karyawan yang tidak ikut pelatihan ataupun tidak fokus dalam mengikuti pelatihan-pelatihan mengenai keselamatan dan kesehatan kerja maupun pelatihan pemahaman hukum yang berlaku.

\section{IV.DAFTAR PUSTAKA}

\section{Buku}

Amirudin dan Zainal Asikin, 2004, Pengantar Metode Penelitian Hukum, PT. Raja Grafindo Persada, Jakarta 
Basir Barthos, Manajemen Sumber Daya Manusia Pendekatan Makro

Burhannudin A Tayibnapsis, 1995,Aministrasi Kepegawaian: Suatu Tinjauan Analitik Pradnya Paramita, Jakarta

Eko Wahyudin Dan Wiwin Yulianingsih, 2016, Hukum Ketenagakerjaan ,Sinar Grafika , Jakarta

Indriarsono, $\mathrm{R}$ Dan $\mathrm{M} \quad \mathrm{J}$ Sapptenno, 1996, Hukum Perburuhan(Perlindungan Hukum Bagi Tenaga Kerja dalam Program Jaminan Sosial Tenaga Kerja), Karunia, Surabaya

Ginting,Jamin, 2007, Hukum Perseroan Terbatas(Undang-Undang Nomor 40 Tahun 2007), PT.Citra Bakti, Bandung

Sendjum H Manulang, 2008, Pokok-Pokok Hukum Ketenagakerjaan di Indonesia, Cet III, Rineka Cipta, Jakarta

\section{Peraturan Perundang-undangan}

Undang-Undang Dasar Negara Republik Indonesia Tahun 1945

Undang-Undang Tentang Keselamatan Kerja

Undang-Undang Nomor 1 Tahun 1970 Tentang Keselamatan Kerja,

(Lembaran Negara Republik Indonesia Nomor 1 Tahun 1970, Tambahan Lembaran Negara Nomor 2918)

Undang-Undang Tentang Ketenagakerjaan

Undang-Undang Nomor 13 Tahun 2003 Tentang

Ketenagakerjaan,(Lembaran Negara Republik Indonesia Nomor 39

Tahun 2003, Tambahan Lembar Negara Nomor 42791)

Undang-Undang Tentang Badan Penyelenggara Jaminan Sosial, Undang-UndangNomor 24 Tahun 2011 Tentang Badan Penyelenggara Jaminan Sosial.(Tambahan Lembaran Negara Republik Indinesia Nomor 5256)

\section{Jurnal Ilmiah}


Marlina Safitri, I Wayan Wiryawan dan Iis Afatiah, Implementasi Sosialisasi Jaminan Kesehatan Nasional (studidi Kelurahan Langka Pura,Kecamatan Langka Pura,Kota Bandar Lampung),Jaminan Keselamatan dan Kesehatan Kerja Menurut Hukum Positif. 